\title{
ERRATUM
}

\section{Erratum to: Pulsed EPR spectroscopy}

\section{Maurice van Gastel}

Published online: 19 September 2009

(C) Springer Science+Business Media B.V. 2009

\section{Erratum to: Photosynth Res}

\section{DOI 10.1007/s11120-009-9422-6}

There are two errors in the 'Applications' section (subsection 'Pulsed EPR of $A_{1}$ in photosystem I') of the original publication.

(1) Fifth page, right column, sixth line: "pattern of five" should be "pattern of six".

(2) Fifth page, right column, eighth line: "Two patterns of five signals" should be "Two patterns of six signals".

The online version of the original article can be found under doi: $10.1007 / \mathrm{s} 11120-009-9422-6$.

M. van Gastel ( $\square)$

Insitut für Physikalische und Theoretische Chemie, Rheinische

Friedrich-Wilhelms Universität Bonn, Wegeler Strasse 12,

53115 Bonn, Germany

e-mail:vgastel@pc.uni-bonn.de 